\title{
ANÁLISE DOS FATORES QUE LEVAM AS EMPRESAS DE COMÉRCIO VAREJISTA DE MATERIAIS PARA CONSTRUÇÃO A TERCEIRIZAREM OS SERVIÇOS CONTÁBEIS
}

\author{
José Edipoan Augusto de Souza Ribeiro ${ }^{1}$ \\ Laércio Juarez Melz ${ }^{2}$ \\ Priscila Meliane Leite dos Anjos ${ }^{3}$ \\ Marcelo Evandro Alves ${ }^{4}$
}

\section{RESUMO}

A pesquisa teve como objetivo verificar quais são os fatores que levam uma empresa a optar pela terceirização dos serviços prestados pelo contador, analisar o grau de satisfação e também a importância dos fatores, destacando as vantagens e desvantagem desse procedimento, pois o contador deve auxiliar o empresário na tarefa de administrar os negócios. Foram utilizadas as metodologias de pesquisa bibliográfica, explicativa e survey. Com este trabalho verificou demonstrar que a utilização da prestação de serviços de um profissional contábil é primordial para a manutenção de uma empresa no mercado atual. A terceirização de serviços contábeis é uma estratégia encontrada pelas empresas de materiais para construção, como forma de enfrentar a concorrência, reduzir as despesas e melhorar o recurso financeiro disponível. $\mathrm{O}$ fator que obteve destaque no que diz em relação às empresas de materiais para construção a optar pela terceirização dos serviços contábeis foi à redução dos custos, pois para uma empresa de pequeno ou médio porte, às vezes tornaria inviável a manutenção do departamento contábil internamente. Também foi apontada como vantagem a qualidade dos serviços contábeis prestados pelos escritórios.

Palavras-chave: Terceirização. Análise de vantagens e desvantagens. Contabilidade.

\section{INTRODUÇÃO}

Os serviços contábeis são fundamentais para as organizações empresariais. Muitas procurando reduzir custos utilizam-se da terceirização destes serviços. Este procedimento é muito utilizado pelas microempresas, empresas de pequeno e médio porte, por ser inviável manter estes serviços dentro do recinto da própria empresa (NUNES, 2009).

Os objetivos da terceirização dos serviços contábeis devem ser claros em qualquer organização e precisam ser apoiados em fatores que realmente possam justificar essa decisão. O corte de custo não deve ser o único motivo para isso, caso contrário as expectativas poderão ser frustrantes (NUNES, 2009).

\footnotetext{
1 Acadêmico do curso de Ciências Contábeis da UNEMAT - Campus de Tangará da Serra, e-mail: naopide_esoj@hotmail.com.

2 Mestre em Engenharia de Produção (UFSCar), Professor do Departamento de Ciências Contábeis da UNEMAT- Campus de Tangará da Serra, e-mail: laercio@ unemat.br.

${ }^{3}$ Profissional técnica da UNEMAT Campus de Tangará da Serra.

${ }^{4}$ Professor do Departamento de Ciências Contábeis da UNEMAT- Campus de Tangará da Serra.
} 
Análise dos fatores que levam as empresas de comércio varejista de materiais para construção a

terceirizarem os serviços contábeis

José Edipoan Augusto de Souza Ribeiro

Laércio Juarez Melz

Priscila Meliane Leite dos Anjos

Marcelo Evandro Alves

A realização das atividades organizacionais por pessoas jurídicas distintas da organização tem sido definida como terceirização. Consiste em transferir a terceiros a execução de tarefas para as quais a relação custo/benefício da execução interna não é das mais vantajosas, seja do ponto de vista financeiro, de qualidade, ou mesmo de especialidade.

$\mathrm{O}$ artigo teve o objetivo geral de verificar quais os fatores que levam as empresas varejistas de materiais de construção de Tangará da Serra - MT a terceirizarem a prestação de serviços. Como objetivos específicos: 1) apresentar as características dos empresários ou gerentes do varejo de materiais para construção; 2) analisar se a prestação de serviços contábeis auxiliam na tomada de decisões; 3) as vantagens e desvantagens de terceirizar o serviço contábil.

\section{REFERENCIAL TEÓRICO}

A Contabilidade surgiu para que o empresário estivesse ciente sobre a saúde financeira de sua empresa. Mas geralmente exige dos profissionais um maior comprometimento em relação ao desempenho de seus clientes. Com o uso das informações contábeis para fins gerenciais, de modo a analisar e monitorar os resultados obtidos no período houve uma melhora nas tomadas de decisões nos diferentes níveis hierárquicos. Porém, o sistema utilizado deve responder de maneira eficaz ao controle administrativo e informacional aplicado (LONDERO; PERES; CHARAO, 2005).

A Contabilidade ainda é vista como um mal necessário dentro da empresa, isso porque para alguns gerenciadores ela é um instrumento de controle dos assuntos fiscais. Além disso, a complexidade de alguns relatórios faz com que usuários na qual não possuam conhecimento do que estão lidando que acabam desconsiderando as informações ou até mesmo não conseguem entender o que cada relatório demonstra (TASSO, 2005).

\subsection{A Evolução da Contabilidade}

A contabilidade tem evoluído juntamente com o crescimento sócio econômico global, tornando-se um instrumento importante de informação e análise empresarial, fazendo com que o contador seja o principal elemento na gestão de informações qualificadas para a tomada de decisões na empresa (LONDERO; PERES; CHARAO, 2005).

De acordo com Fortes (2001), ainda não foi inventado um sistema de registro, controle e análise patrimonial para a gestão do patrimônio das entidades que seja mais eficiente do que 
Análise dos fatores que levam as empresas de comércio varejista de materiais para construção a

terceirizarem os serviços contábeis

José Edipoan Augusto de Souza Ribeiro

Laércio Juarez Melz

Priscila Meliane Leite dos Anjos

Marcelo Evandro Alves

a contabilidade. É a partir dessas informações geradas pela contabilidade que os administradores tomam decisões empresariais, sempre em busca de seus interesses pessoais.

No entanto, a função de um profissional contábil perante alguns seguimentos da nossa economia, principalmente nas micro e pequenas empresas, infelizmente vem sendo distorcida e utilizada apenas com o intuito de atender a exigências fiscais (NASI, 1994).

\section{2 Área de Atuação da Contabilidade}

A área de atuação da contabilidade compreende qualquer entidade, pessoa física ou jurídica, que tenha seu patrimônio definido e delimitado. Ela procura prestar colaboração a essas, não apenas para sua gestão, mas até para sua própria continuidade, visto que sem controle e sem informações fornecidas pela Contabilidade, seria impossível a tais organismos alcançarem suas finalidades (MULLER; OLIVEIRA, 2003).

Para Iudícibus (1998) a contabilidade é uma metodologia especialmente concebida para captar, registrar e interpretar os fenômenos que afetam as situações patrimoniais, financeiras e econômicas de qualquer organização, seja pessoa física ou jurídica, como também entidades de finalidades não lucrativas ou pessoa do Direito Público.

Ott (2004) destaca que cada área de atuação da contabilidade atende a demanda de informações e usuários distintos. À contabilidade financeira cabe o fornecimento de informações financeiras, fiscais e legais para usuários externos. A contabilidade gerencial e de custos deve gerar informações para fundamentar a tomada de decisão dos gestores (usuários internos) enfocando a maximização dos resultados e a mensuração do desempenho dos departamentos, produtos e respectivos dirigentes.

A contabilidade financeira tem como atribuição registrar, classificar e analisar os fatos contábeis oriundos das transações que se produzem entre o ambiente externo e a empresa. Expressa a situação periódica do patrimônio e os resultados obtidos pela empresa em sua atividade econômica. Apresenta a situação patrimonial e de caráter histórico para os diversos usuários externos que a desejam conhecer e ter garantia da capacidade empresarial em gerar resultados futuros (VOLNEI et al., 2007).

Assim, verifica-se como sua principal função, gerar informações que possibilitem aos seus usuários, tanto internos quanto externos à entidade, conhecer a realidade financeira dessa unidade econômica e, com essa base, estarem capacitados a tomar decisões (OTT, 2004). 
Análise dos fatores que levam as empresas de comércio varejista de materiais para construção a

terceirizarem os serviços contábeis

José Edipoan Augusto de Souza Ribeiro

Laércio Juarez Melz

Priscila Meliane Leite dos Anjos

Marcelo Evandro Alves

A contabilidade gerencial é definida como o processo de identificação, mensuração, acumulação, análise, preparação, interpretação e comunicação de informação para a tomada de decisão dos gestores, visando o planejamento, avaliação e controle do uso dos recursos organizacionais e responsabilização dos gestores por suas decisões. É uma atividade executada de forma interligada ao processo gerencial da organização, focada no uso dos recursos pelas pessoas de forma dinâmica e competitiva para a criação de valor (VOLNEI et al., 2007).

Ott (2004) destaca que a contabilidade gerencial representa uma evolução qualitativa e quantitativa da contabilidade de custos e tem seu foco na tomada de decisões táticas e operacionais dos gestores. Decorre de estudos realizados, devido às críticas e a necessidade de evolução dos sistemas de informação até então utilizados e que não atendiam a demanda das empresas para se manterem competitivas em um ambiente instável, incerto, com uma evolução tecnológica constante e com as novas técnicas revolucionárias de gestão.

Quadro 1: Contabilidade Financeira x Contabilidade Gerencial:

\begin{tabular}{|c|c|c|}
\hline FATOR & CONTABILIDADE FINANCEIRA & CONTABILIDADE GERENCIAL \\
\hline $\begin{array}{l}\text { Objetivos dos } \\
\text { relatórios e seus } \\
\text { destinatários }\end{array}$ & $\begin{array}{l}\text { Facilitar a análise financeira dos usuários } \\
\text { externos }\end{array}$ & $\begin{array}{l}\text { Facilitar o planejamento, controle, avaliação de desempenho } \\
\text { e tomada de decisões pelos usuários internos. }\end{array}$ \\
\hline $\begin{array}{l}\text { Espécies e } \\
\text { forma dos } \\
\text { relatórios }\end{array}$ & $\begin{array}{l}\text { BP, DRE, DLPA (DMPL), DFC e DVA, } \\
\text { conforme os moldes legais, elaborados de } \\
\text { forma resumida, preocupando-se } \\
\text { precipuamente com a entidade como um } \\
\text { todo. }\end{array}$ & $\begin{array}{l}\text { Orçamentos, relatórios de desempenho, de custos e outros } \\
\text { não rotineiros para facilitar a tomada de decisões, elaborados } \\
\text { de forma detalhada, com especificidades de partes da } \\
\text { entidade, como produtos, departamentos etc. }\end{array}$ \\
\hline $\begin{array}{l}\text { Frequência dos } \\
\text { relatórios e seu } \\
\text { horizonte } \\
\text { temporal }\end{array}$ & $\begin{array}{l}\text { Relatórios anuais, semestrais ou } \\
\text { trimestrais, conforme a legislação, com } \\
\text { abrangência desse período. }\end{array}$ & $\begin{array}{l}\text { Relatórios produzidos sempre que necessários pela } \\
\text { administração, com horizonte temporal variável, que vai } \\
\text { desde horas a vários anos. }\end{array}$ \\
\hline $\begin{array}{l}\text { Restrições nas } \\
\text { informações }\end{array}$ & Princípios Fundamentais de Contabilidade. & $\begin{array}{l}\text { Sem restrições, salvo as determinadas pela própria } \\
\text { administração, como custos ou relevância das informações. }\end{array}$ \\
\hline $\begin{array}{l}\text { Características } \\
\text { da informação }\end{array}$ & $\begin{array}{l}\text { Somente para mensuração financeira e } \\
\text { econômica, sendo objetiva, verificável, } \\
\text { relevante e tempestiva. }\end{array}$ & $\begin{array}{l}\text { Deve ser relevante e tempestiva, podendo ser subjetiva, } \\
\text { desde que isso não prejudique a qualidade da informação. }\end{array}$ \\
\hline $\begin{array}{l}\text { Perspectiva dos } \\
\text { relatórios }\end{array}$ & Orientação histórica. & $\begin{array}{c}\text { Orientação para o futuro (planejamento, } \\
\text { avaliação de desempenho e estabelecimento } \\
\text { de metas) e histórica (avaliação de } \\
\text { resultados obtidos para orientar a tomada } \\
\text { de decisões futura). }\end{array}$ \\
\hline
\end{tabular}

Fonte: Oliveira (2012). 
Análise dos fatores que levam as empresas de comércio varejista de materiais para construção a

terceirizarem os serviços contábeis

José Edipoan Augusto de Souza Ribeiro

Laércio Juarez Melz

Priscila Meliane Leite dos Anjos

Marcelo Evandro Alves

\subsection{Prestação de Serviços}

A prestação de serviços é um trabalho realizado por uma empresa, seja pessoa jurídica de direito privado ou pessoa física, de natureza comercial a "título de aluguel” de mão de obra física ou intelectual, sem vínculo empregatício, instaladas nas imediações físicas da empresa contratante ou em outro local por ela determinado mediante remuneração do tomador para com o prestador (MATTOS; DIAS; GONÇALVES, 2006).

\subsection{Terceirização}

Já Martins (2001) define que a terceirização consiste na possibilidade de contratar terceiro para a realização de atividades que não constituem o objeto principal da empresa. Essa contratação pode envolver tanto a produção de bens como serviços, como ocorre na necessidade de contratação de serviços de limpeza de vigilância ou até de serviços temporários.

Adotando a terceirização, a empresa poderá concentrar seus recursos e esforços na sua própria área produtiva, na área em que é especializada, melhorando a qualidade do produto e sua competitividade no mercado (IMHOFF; MORTARI, 2005).

Para Bernstorff e Cunha (2005), define também como “outsourcing”, expressão em inglês, que significa terceirização, referenciado sempre pela concepção estratégica de prática. É considerada como um processo de gestão pelo qual se repassam algumas atividades para terceiros, com os quais se estabelece uma relação de parceria, ficando a empresa concentrada apenas em tarefas essencialmente ligadas ao negócio em que atua.

\subsection{Vantagens e desvantagens da terceirização}

A terceirização como qualquer modelo de gestão apresenta vantagens e desvantagens para a empresa e devem ser levadas em consideração.

Segundo Martins (2001, p.42), uma das vantagens sob o aspecto administrativo, seria a de se ter alternativa para melhorar a qualidade o produto ou serviço vendido e também a produtividade. Seria uma forma também de se obter um controle de qualidade total dentro da empresa, sendo que um dos objetivos básicos dos administradores é a diminuição de encargos trabalhistas e previdenciários, além da redução do preço final do produto ou serviço. 
Análise dos fatores que levam as empresas de comércio varejista de materiais para construção a

terceirizarem os serviços contábeis

José Edipoan Augusto de Souza Ribeiro

Laércio Juarez Melz

Priscila Meliane Leite dos Anjos

Marcelo Evandro Alves

Para Imhoff e Mortari (2005), as desvantagens para o trabalhador, pode-se indicar a perda do emprego, no qual tinha remuneração certa por mês, passando a incerta, além da perda dos benefícios sociais decorrentes do contrato de trabalho e das normas coletivas da categoria e também o custo das demissões que ocorrem na fase inicial.

\subsection{Funções contábeis e gerenciais do contador}

O contador pode exercer funções importantes nas empresas. Entre elas está a elaboração do fluxo de caixa, análise das demonstrações contábeis e análise de custos. Além de participação na elaboração do planejamento estratégico da empresa. O contador também exerce as funções regulares da contabilidade como elaborar as demonstrações contábeis, declarações exigidas pelo fisco.

O fluxo de caixa é uma demonstração dinâmica, que oferece ao gerente financeiro uma bagagem de informações que o ajudará na tomada de decisões. Representa a previsão, o controle e o registro de entradas e saídas financeiras durante um determinado período, contendo informações sobre a vida financeira da empresa. Através dele, obtêm-se as informações sobre o estado de liquidez da empresa; como utilizar seus recursos por um determinado período; se há capacidade da empresa aplicar recursos e/ou se há necessidade de buscar um empréstimo (PIVETTA, 2005).

Segundo Kotler (1992) planejamento estratégico é definido como o processo gerencial de desenvolver e manter uma adequação razoável entre os objetivos e recursos da empresa e as mudanças e oportunidades de mercado. $\mathrm{O}$ objetivo do planejamento estratégico é orientar e reorientar os negócios e produtos da empresa de modo que gere lucros e crescimento satisfatórios.

Para Leone (1997), tratando-se de custos, referem-se ao valor dos fatores de produção consumidos por uma firma para produzir ou distribuir produtos ou serviços, ou ambos. Já Martins (1992) refere-se a custos como gasto relativo à bem ou serviço utilizado na produção de outros bens e serviços, ou seja, o valor dos insumos usados na fabricação dos produtos da empresa. Salienta que o custo é também um gasto, só que reconhecido como tal, isto é, como custo, no momento da utilização dos fatores de produção (bens e serviços) para fabricação de um produto ou execução de um serviço. 
Análise dos fatores que levam as empresas de comércio varejista de materiais para construção a

terceirizarem os serviços contábeis

José Edipoan Augusto de Souza Ribeiro

Laércio Juarez Melz

Priscila Meliane Leite dos Anjos

Marcelo Evandro Alves

\subsection{Demonstrações e relatórios/documentos contábeis}

O balanço patrimonial é a demonstração contábil destinada a evidenciar, qualitativamente e quantitativamente, numa determinada data, o patrimônio e o patrimônio líquido da entidade. Essa demonstração deve compreender todos os bens e direitos, tanto tangíveis como intangíveis, as obrigações e o patrimônio líquido da Entidade (RIBEIRO, 2009). O Balanço Patrimonial é o relatório mais importante da contabilidade e se divide em ativo e passivo. Tal importância se dá por ser utilizado para verificar a situação patrimonial e financeira de uma empresa ou entidade (MARION, 1998).

A análise das demonstrações contábeis tem por objetivo observar e confrontar os elementos patrimoniais e os resultados das operações, visando ao conhecimento minucioso de sua composição qualitativa e de sua expressão quantitativa, de modo a revelar os fatores antecedentes e determinantes da situação atual, e, também, a servir de ponto de partida para delinear o comportamento futuro da empresa. (OLIVEIRA, et al, 2010).

O objetivo das demonstrações contábeis é fornecer informações sobre a posição patrimonial e financeira, o desempenho e as mudanças na posição financeira da entidade, que sejam úteis a um grande número de usuários em suas avaliações e tomadas de decisão econômica. As demonstrações contábeis também objetivam apresentar os resultados da atuação da administração na gestão da entidade e sua capacitação na prestação de contas quanto aos recursos que lhe foram confiados. Aqueles usuários que desejam avaliar a atuação ou prestação de contas da administração fazem-no com a finalidade de estar em condições de tomar decisões econômicas que podem incluir, por exemplo, manter ou vender seus investimentos na entidade, reeleger ou substituir a administração (CRC-PR, 2011).

Aliando dados físicos aos monetários e utilizando-se conceitos financeiros, vários relatórios de muita utilidade podem ser gerados pelo contador. Tais relatórios, além de proporcionar mais segurança na tomada de decisão, possibilitam a inserção do contador neste processo. Desta forma, estará o contador gerando diversas versões da informação contábil, uma para cada usuário e para cada propósito, evitando o que ocorre hoje, em que os destinatários usam os relatórios emitidos pela contabilidade como fontes de dados, processam em modelos ou programas acessórios para, só então, serem transformados em informações úteis à tomada de decisão (FERREIRA; DUTRA; CARDOSO, 2000). 
Análise dos fatores que levam as empresas de comércio varejista de materiais para construção a

terceirizarem os serviços contábeis

José Edipoan Augusto de Souza Ribeiro

Laércio Juarez Melz

Priscila Meliane Leite dos Anjos

Marcelo Evandro Alves

Da mesma forma que o usuário ou consumidor de um bem o quer de forma diferenciada, o usuário da informação a quer também de forma personalizada e que atenda a sua necessidade específica. Em outras palavras, deve o contador ser capaz de gerar a informação, segregando-a por usuário ou grupo de usuários, de forma que cada um só receba aquelas que realmente interessam, levando-se em consideração as respectivas atribuições e responsabilidades. Além disto, elas devem estar em "linguagem" compreensível, dispensando-se, intérpretes, ou seja, fazendo com que os relatórios gerados pelos contadores sejam o bastante para atender as necessidades e expectativas dos usuários. Elas devem dispensar qualquer outro processamento, afinal, já são informações, diferente de dados (FERREIRA; DUTRA; CARDOSO, 2000).

O SPED - Sistema Público de Escrituração Digital - de modo geral, consiste na modernização da sistemática atual do cumprimento das obrigações acessórias, transmitidas pelos contribuintes às administrações tributárias e aos órgãos fiscalizadores, utilizando-se da certificação digital para fins de assinatura dos documentos eletrônicos, garantindo assim a validade jurídica dos mesmos apenas na sua forma digital (ESPERANDIO; MELO; MATA, 2011).

\subsection{Contador x Administrador}

A principal função do contador é executar a contabilidade geral, financeira e gerencial, na área específica, além de outras atividades importantes, bem como disponibilizar informações referentes aos atos relativos à gestão econômico-financeira da organização. Entretanto, o contador está constantemente exposto a questionamentos éticos, que se devem ao fato de que os mesmos estão diretamente ligados aos fatos econômicos e financeiros das empresas, nas quais atuam ou prestam serviços (NUNES; FREITAS, 2004).

Segundo Nasi (1994, p. 5), para o contador não perder espaço para outros profissionais:

O contador deve estar no centro, na liderança do processo, pois do contrário, seu lugar vai ser ocupado por outro profissional. O contador deve saber comunicar-se com outras áreas da empresa. Para tanto não pode ficar com os conhecimentos restritos aos temas contábeis e fiscais, inteirando-se do que aconteça ao seu redor, na sua comunidade, no seu Estado, no seu país, no mundo. O contador deve ter um comportamento ético - profissional inquestionável. O contador deve participar de eventos destinados à sua permanente atualização profissional (educação continuada). 
Análise dos fatores que levam as empresas de comércio varejista de materiais para construção a

terceirizarem os serviços contábeis

José Edipoan Augusto de Souza Ribeiro

Laércio Juarez Melz

Priscila Meliane Leite dos Anjos

Marcelo Evandro Alves

$\mathrm{O}$ administrador também deve ter visão ampla a respeito de todas as atividades e informações que circulam dentro da empresa, pois o contador fornece dados consistentes e de fácil interpretação sobre todas as operações da empresa, o administrador deve possuir capacidade para utilizar e analisar esses dados, afim de que ele possa desenvolver estratégias e tomar decisões a respeito dos riscos e retornos inerentes ao negócio (LONDERO; PERES; CHARAO, 2005).

\section{METODOLOGIA}

Pode-se classificar a pesquisa com relação à abordagem do problema, quanto aos procedimentos e quanto aos objetivos (BEUREN et al, 2003). Quanto aos objetivos, trata-se de pesquisa explicativa. A pesquisa explicativa pretende explicar os motivos pelo qual acontece algum fenômeno, neste caso os motivos pela empresa optar por contratar serviços contábeis terceirizados.

Quanto aos procedimentos trata-se de pesquisa bibliográfica no que se refere às atribuições do contador e levantamento, survey, para obter os dados junto às empresas. $\mathrm{O}$ método survey é uma pesquisa para obtenção de informações sobre características, ações e opiniões de determinado grupo de pessoas, indicado como representante de uma populaçãoalvo, por meio de um instrumento de pesquisa, normalmente um questionário. $\mathrm{O}$ foco do interesse é sobre "o que está acontecendo, como e por que" (ARRUDA; COZZI; SILVEIRA, 2012). O universo de empresas em Tangará da Serra é de 22 empresas, conforme dados coletados na Prefeitura Municipal de Tangará da Serra - MT.

O trabalho tem ênfase à pesquisa bibliográfica, pois se baseia na pesquisa elaborada a partir de estudos já realizados (BEUREN, et al, 2003). E também foi realizada pesquisa de campo, na qual é uma fase realizada após o estudo bibliográfico, para que o pesquisador tenha um bom conhecimento sobre o assunto (LAKATOS e MARCONI, 1991).

Esta pesquisa foi realizada no $1^{\circ}$ (primeiro) semestre de 2012, sendo aplicados questionários fechados em 22 (vinte e duas) empresas que comercializam materiais para construção em Tangará da Serra - MT, entregues pessoalmente, para verificar o que leva as empresas terceirizarem os serviços contábeis, porém das 22 empresas entrevistadas somente 2 (duas) não responderam o questionário. Este, foi respondido por gerentes ou proprietários das empresas. 
Análise dos fatores que levam as empresas de comércio varejista de materiais para construção a terceirizarem os serviços contábeis

José Edipoan Augusto de Souza Ribeiro

Laércio Juarez Melz

Priscila Meliane Leite dos Anjos

Marcelo Evandro Alves

\section{RESULTADOS}

\subsection{Características dos entrevistados}

O administrador é o responsável pela execução do planejamento, que é uma das funções administrativas para o sucesso da empresa. Planejar significa pensar antes das ações que se desenvolverão futuramente. O planejamento possui basicamente duas funções: estratégica e operacional. A função estratégica é desenvolvida mediante a avaliação das oportunidades e ameaças que vêm de fora da empresa, para que se possa ter uma visão e um alto nível de envolvimento e conhecimento da estrutura do negócio da empresa. $\mathrm{O}$ planejamento operacional é feito nos níveis mais baixos, e seu enfoque são as atividades do momento e sua principal preocupação é a eficiência em vez da eficácia. (LONDERO; PERES; CHARAO, 2005).

Percebeu-se que a maioria dos entrevistados, de acordo com a tabela 1, é do sexo masculino (68\%), e o restante é feminino com $32 \%$. A maior parte do público pesquisado foi na faixa etária de 31 a 40 anos (47\%) e também com ênfase de 20 a 30 anos que foi em 32\% (tabela 2). Com maior relevância os empresários possuem ensino superior completo (42\%) ou incompleto $(21 \%)$. Grande número possui o ensino médio completo (32\%). Poucos entrevistados tem pós-graduação (tabela 3).

Tabela 1: Sexo dos empresários/responsáveis das empresas entrevistadas, em \%:

\begin{tabular}{cc}
\hline SEXO & $\boldsymbol{\%}$ \\
\hline Masculino & $68 \%$ \\
Feminino & $32 \%$ \\
\hline TOTAL GERAL & $\mathbf{1 0 0 \%}$ \\
\hline
\end{tabular}

Tabela 2: Faixa etária dos empresários, em \%:

\begin{tabular}{lcc}
\hline & IDADE & $\%$ \\
\hline & De 20 a 30 anos & $32 \%$ \\
& De 31 a 40 anos & $47 \%$ \\
& De 41 a 50 anos & $16 \%$ \\
& Acima de 50 anos & $5 \%$ \\
\hline Volume 1, Número 2 & & Revista UNEMAT de Contabilidade \\
Jul./dez. 2012 & & UNEMAT
\end{tabular}


Análise dos fatores que levam as empresas de comércio varejista de materiais para construção a terceirizarem os serviços contábeis

José Edipoan Augusto de Souza Ribeiro

Laércio Juarez Melz

Priscila Meliane Leite dos Anjos

Marcelo Evandro Alves

TOTAL GERAL

Tabela 3: Grau de escolaridade dos empresários/responsáveis das empresas entrevistadas, em \%:

GRAU DE ESCOLARIDADE

$1^{\mathrm{o}}$ grau completo

$0 \%$

$1^{\mathrm{o}}$ grau incompleto

$0 \%$

$2^{\circ}$ grau completo

$2^{\circ}$ grau incompleto

$32 \%$

$0 \%$

Ensino Superior Completo

Ensino Superior Incompleto

Pós-graduação, Mestre ou Doutor.

$5 \%$

TOTAL GERAL

\subsection{Análise da prestação de serviços contábeis como apoio à decisão}

Conforme Figueiredo e Fabri (2000), o profissional de contabilidade, além dos conhecimentos técnicos e necessários ao desempenho da atividade, deve conhecer o ambiente interno e externo das organizações. Deverá ser capacitado plenamente para o domínio da linguagem dos negócios, pois é o responsável pelo ambiente de geração de informações fundamentais ao processo decisório/estratégico das organizações.

O contador não tem como única função o atendimento de obrigações fiscais, mas é sua responsabilidade informar à administração sobre $\mathrm{o}$ andamento dos negócios. Mais recentemente, a função do contador sofre influência da tecnologia, demonstrando que as funções de escrituração contábil e arquivo começaram a diminuir, dando lugar, com mais destaque, à análise contábil e a melhoria dos controles contábeis e financeiros (SILVA, 2009).

$\mathrm{Na}$ figura 1 estão os resultados obtidos nas empresas sobre a função que o contador exerce na organização. Os resultados apontaram que a maioria dos entrevistados, $45 \%$, vê o 
Análise dos fatores que levam as empresas de comércio varejista de materiais para construção a terceirizarem os serviços contábeis

José Edipoan Augusto de Souza Ribeiro

Laércio Juarez Melz

Priscila Meliane Leite dos Anjos

Marcelo Evandro Alves

papel do contador como apenas para apurar os impostos a serem pagos. Percebeu-se que a assessoria para tomada de decisão é o papel secundário que o contador deve exercer nas empresas varejistas de materiais de construção. Essa postura contrapõe-se à doutrina contábil que estabelece que o contador deveria ser fonte de informação para a decisão gerencial.

Figura 1. Resposta dos entrevistados com relação ao papel do contador na empresa varejista de materiais de construção Tangará da Serra, 2012, em \%:

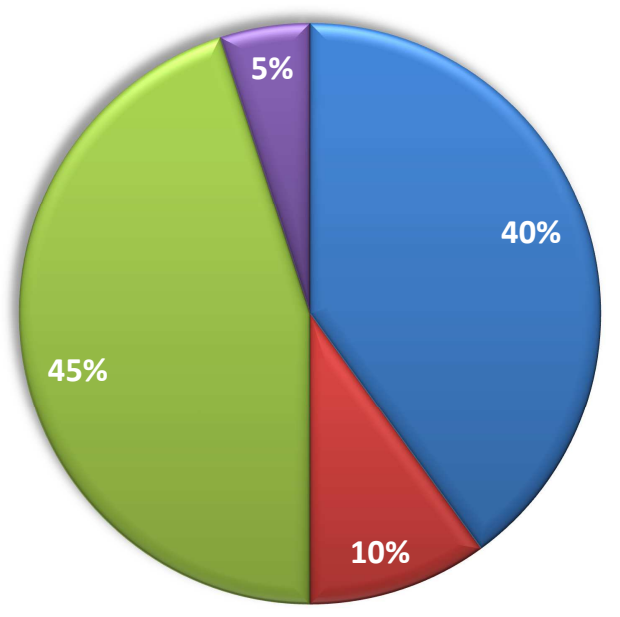

\section{$\square$ Assessoria para tomada de decisão}

口Assessoria em como melhor investir ou aplicar o dinheiro da empresa

$\square$ Apenas para apurar os impostos a serem pagos (FISCO)

$\square$ Não responder

De acordo com Fortes (2001), ainda não foi inventado um sistema de registro, controle e análise patrimonial para a gestão do patrimônio das entidades que seja mais eficiente do que a contabilidade. A partir dessas informações geradas pela contabilidade que os usuários tomam decisões empresariais, sempre em busca de seus objetivos tanto pessoais quanto profissionais. Como é visto na figura 2, percebe-se que há igualdade entre as formas utilizadas das informações contábeis pelas empresas: em apenas atender as exigências do Fisco e também para traçar metas e desenvolver ações de crescimento da empresa, com $42 \%$ cada. Já $11 \%$ dos entrevistados preferiram não informar de que forma são utilizadas as informações dentro da organização, outros 5\% definiram que obtêm as informações para saber sobre o giro do estoque, qual produto tem uma demanda e oferta mais em evidência do que a outra.

Figura 2: Respostas dos entrevistados sobre quais formas utilizadas das informações contábeis repassadas pelo contador, em $\%$ : 
Análise dos fatores que levam as empresas de comércio varejista de materiais para construção a

terceirizarem os serviços contábeis

José Edipoan Augusto de Souza Ribeiro

Laércio Juarez Melz

Priscila Meliane Leite dos Anjos

Marcelo Evandro Alves

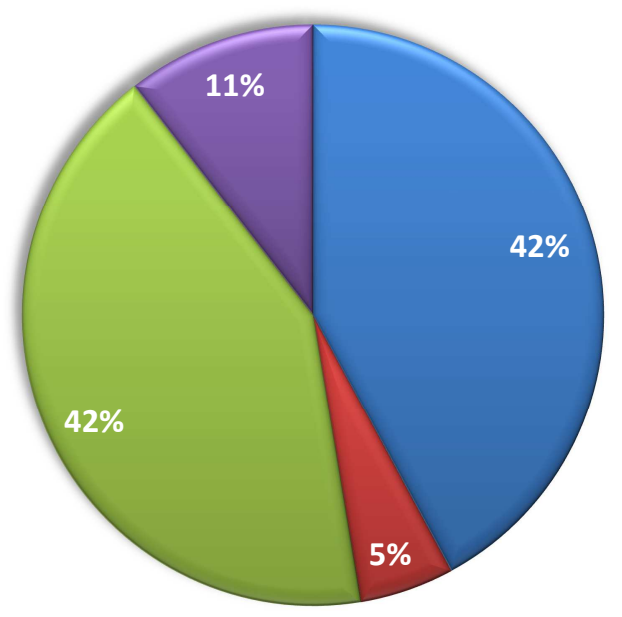

$\square$ Apenas para atender as

exigências do Fisco

๑Obter informações sobre o

giro do estoque

$\square$ Para traçar metas e desenvolver ações de crescimento da empresa

$\square$ Não responder

Das informações fornecidas pela contabilidade destacam-se as formalidades de escrituração, as demonstrações contábeis, a auditoria e a análise de balanços, que são registros e organização dos fatos que refletem seu estado patrimonial, financeiro e de resultado. Para uma interpretação eficaz da contabilidade, em função da administração da empresa, é necessário saber analisar os relatórios contábeis, traçar um planejamento e efetuar o controle da organização. O planejamento é uma maneira de determinar a direção que a empresa seguirá de acordo com as decisões tomadas. É importante saber o rumo certo a seguir, aplicar os recursos disponíveis com a máxima eficiência, constituindo isso um fator decisivo para o crescimento da organização (LONDERO; PERES; CHARAO, 2005).

A ciência contábil tem por fim produzir informações verídicas sobre o patrimônio empresarial para os seus demais usuários, os quais possuem interesses naquelas. Tais informações, além de verdadeiras, devem ser íntegras e claras quanto às quantidades e qualidades dos termos físicos e monetários da entidade (NUNES; FREITAS, 2004).

No entanto atualizar as informações contábeis é uma atitude que faz a diferença atualmente, fazendo com que as informações relacionadas a cada área assumam posição de transparência para a sociedade (QUEIROZ, 1992). E Lopes de Sá (2008) afirma que, a finalidade da escrituração contábil é permitir que se obtenham elementos de julgamento sobre a qualidade do desempenho da riqueza patrimonial, ou seja, se realmente ela cumpre ou não os objetivos que a constituíram. Na tabela 4 e 5, foi avaliado a importância e o grau de satisfação dos serviços contábeis dentro do ambiente organizacional, respectivamente, nota-se 
Análise dos fatores que levam as empresas de comércio varejista de materiais para construção a terceirizarem os serviços contábeis

José Edipoan Augusto de Souza Ribeiro

Laércio Juarez Melz

Priscila Meliane Leite dos Anjos

Marcelo Evandro Alves

que $89 \%$ dos entrevistados afirmam que a contabilidade é uma ferramenta gerencial muito importante para tomada de decisões e outros $11 \%$ classificam como importante.

Tabela 4: Opinião dos empresários em relação à importância da contabilidade nas organizações, em \%:

\begin{tabular}{cc}
\hline IMPORTÂNCIA DA CONTABILIDADE & $\boldsymbol{\%}$ \\
\hline Muito importante & $89 \%$ \\
Importante & $11 \%$ \\
Pouco importante & $0 \%$ \\
Não é importante & $0 \%$ \\
Não respondeu & $0 \%$ \\
\hline TOTAL GERAL & $\mathbf{1 0 0 \%}$ \\
\hline
\end{tabular}

No mesmo pensamento foi analisado o grau de satisfação sobre os serviços prestados, no que $74 \%$ alegaram estarem satisfeitos com as informações prestadas, em contrapartida $21 \%$ não estão satisfeitos, e outros $5 \%$ preferiram não opinar sobre o assunto (Tabela 5).

Tabela 5: O grau de satisfação dos empresários em relação aos serviços contábeis prestados, em \%:

\begin{tabular}{cc}
\hline SATISFAÇÃO DOS SERVIÇOS CONTÁBEIS & $\%$ \\
\hline Sim & $74 \%$ \\
Não & $21 \%$ \\
Não respondeu & $5 \%$ \\
\hline TOTAL GERAL & $\mathbf{1 0 0 \%}$ \\
\hline
\end{tabular}

As informações contábeis divulgadas possuem o objetivo de reduzir a diferença informacional e auxiliar no monitoramento de contratos. Adicionalmente, uma das 
Análise dos fatores que levam as empresas de comércio varejista de materiais para construção a terceirizarem os serviços contábeis

José Edipoan Augusto de Souza Ribeiro

Laércio Juarez Melz

Priscila Meliane Leite dos Anjos

Marcelo Evandro Alves

características qualitativas da informação contábil é a de que a mesma deve ser relevante para o usuário, contendo valor preditivo (LOPES; MARTINS, 2005). Nota-se na tabela 6 que $87,50 \%$ dos entrevistados que apontaram que o papel do contador na empresa tem como fundamento atender o fisco, também afirmaram que utilizam os serviços para apurar os impostos a serem pagos. Outro fato relevante é que outros $75 \%$ afirmaram que o papel do contador na organização é de traçar metas para o desenvolvimento dos objetivos ou uma ferramenta importante para a tomada de decisão.

Tabela 6: Qual o papel do contador na empresa e a sua aplicabilidade através das informações, em \%:

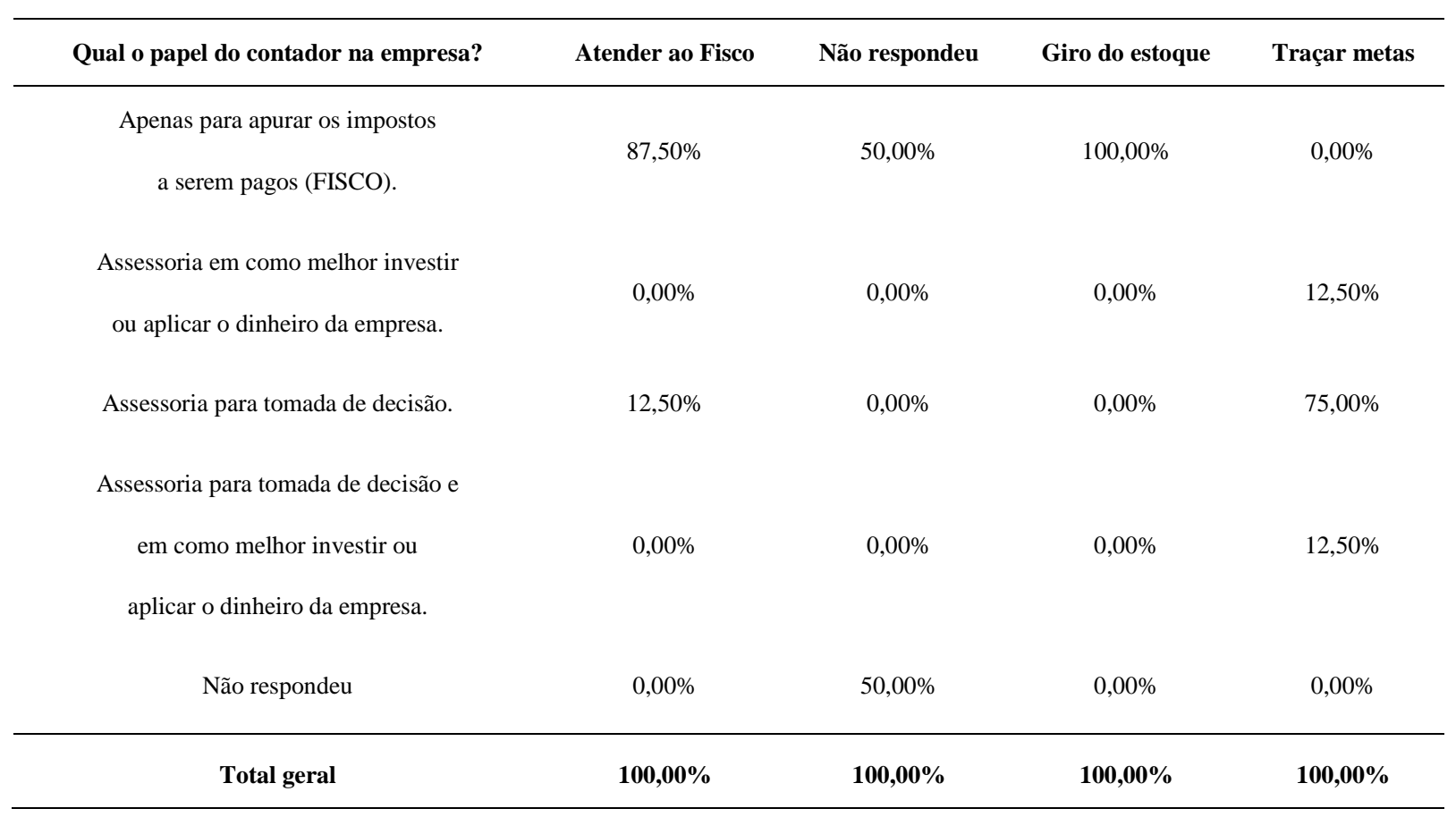

No que diz a respeito ao governo, foi aplicado uma avaliação sobre a manutenção ou não dos serviços contábeis caso não houvesse exigibilidade do governo. Na tabela 7 nota-se que $68 \%$ dos empresários continuariam usando a contabilidade nas organizações, porém há um risco para $21 \%$ dos entrevistados na qual apontaram que não utilizariam os serviços, deixando a empresa exposta ao não conhecimento de custos, giro de estoque, análise de liquidez e consequentemente o descontrole administrativo.

Tabela 7: A opinião dos entrevistados em relação à manutenção dos serviços contábeis caso não houvesse a exigência do governo, em \%: 
Análise dos fatores que levam as empresas de comércio varejista de materiais para construção a terceirizarem os serviços contábeis

José Edipoan Augusto de Souza Ribeiro

Laércio Juarez Melz

Priscila Meliane Leite dos Anjos

Marcelo Evandro Alves

Sim

Não

Não respondeu

$11 \%$

TOTAL GERAL

A tabela 8 permite verificar o período de informações contábeis prestadas para as empresas de comércio de materiais para construção. Nela é notado que 58\% das empresas entrevistadas recebem essas informações mensalmente, outros $32 \%$ recebem semanalmente e $10 \%$ dos entrevistados não expuseram sua opinião ou não souberam responder a periodicidade das informações, atribuídos 5\% para cada.

Tabela 8: Respostas dos entrevistados em relação ao período de informações prestadas pelos contadores para as empresas, em \%:

\begin{tabular}{cc}
\hline PERÍODO DE INFORMAÇÕES & $\%$ \\
\hline Semanal & $32 \%$ \\
Mensal & $58 \%$ \\
Semestral & $0 \%$ \\
Anual & $0 \%$ \\
Não sabe & $5 \%$ \\
Não respondeu & $5 \%$ \\
\hline TOTAL GERAL & $\mathbf{1 0 0 \%}$ \\
\hline
\end{tabular}

\subsection{Vantagens e desvantagens de terceirizar o serviço contábil}

A terceirização faz parte de um processo que possibilita uma maior flexibilização das estruturas jurídicas, que visa compatibilizar o crescimento econômico com a diminuição de 
Análise dos fatores que levam as empresas de comércio varejista de materiais para construção a

terceirizarem os serviços contábeis

José Edipoan Augusto de Souza Ribeiro

Laércio Juarez Melz

Priscila Meliane Leite dos Anjos

Marcelo Evandro Alves

custos combinado com a busca de uma maior produtividade e qualidade, sem que venha prejudicar a preservação dos postos de trabalho, seja na condição de empregado ou por intermédio de qualquer forma de aproveitamento do operário, o mais importante é preservar a ocupação do trabalhador. (COELHO, 2007).

Segundo Martins (2001) a desvantagem deve-se considerar os seguintes fatores:

- A subcontratação, que ocorre de trabalhadores que são intermediários;

- Possível queda na qualidade de serviços, porque não se tem conhecimento dos profissionais que estão ingressando na empresa;

- Dependência da empresa com a prestadora, pois esta terá conhecimentos totais da sua empresa, podendo a qualquer tempo apossar-se deles em detrimento da empresa;

- Perda em determinados casos de fatores importantes no desenvolvimento da produção;

- Problema em princípio no controle de produção, isso porque não se sabe como e quando o produto poderá ser considerado confiável;

- Problemas com prestadoras inidôneas que poderão gerar despesas futuras com lides trabalhistas.

Ao se fazer uma comparação com o resultado obtido com que os gestores consideram relevantes, verificou-se que todos esses fatores relacionados confirmam com Queiroz (1992), a terceirização no Brasil está equivocadamente enfocada para a redução nos custos, o interesse é somente diminuir esquecendo-se do produzir.

O quadro 2 apresenta o detalhamento das respostas dos entrevistados sobre as vantagens e desvantagens da terceirização dos serviços contábeis. Dos entrevistados, 2 apontaram somente desvantagens na terceirização. Os entrevistados que apontaram a redução de custo como vantagem, apontaram como desvantagem, principalmente, a perda de prestigio no mercado. Em contrapartida, nota-se em que outra boa parte dos entrevistados afirmaram que é desvantagem em relação aos serviços contábeis que não contribui com a competitividade do produto no mercado de trabalho (12 entrevistados). Porém 13 empresários apontaram que seria vantajosa a terceirização para melhorar a qualidade do serviço que a empresa de comércio de materiais para construção oferece aos seus clientes, o contador pode analisar o que está sendo vantajoso em saída de estoque ou centralizar os investimentos em propagandas, em inovação de estoques, em treinamento de pessoal entre outros fatores que contribuam com a qualidade do serviço. 
Análise dos fatores que levam as empresas de comércio varejista de materiais para construção a terceirizarem os serviços contábeis

José Edipoan Augusto de Souza Ribeiro

Laércio Juarez Melz

Priscila Meliane Leite dos Anjos

Marcelo Evandro Alves

Quadro 2: Detalhamento das respostas dos entrevistado sobre vantagens e desvantagens de terceirizar os serviços contábeis.

\begin{tabular}{|c|c|c|c|c|c|c|c|c|c|c|c|c|c|c|c|c|c|c|c|c|c|c|c|}
\hline \multicolumn{2}{|c|}{ Respostas } & 1 & 2 & 3 & 4 & 5 & 6 & 7 & 8 & 9 & 10 & 11 & 12 & 13 & 14 & 15 & 16 & 17 & 18 & 19 & 20 & Total & $\%$ \\
\hline \multirow{6}{*}{ 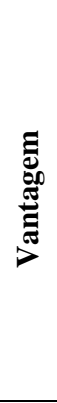 } & Qualidade do serviço & & V & & & $\mathrm{V}$ & V & & V & V & & V & $\mathrm{V}$ & V & V & $\mathrm{V}$ & V & $\mathrm{V}$ & & & $\mathrm{V}$ & 13 & $65 \%$ \\
\hline & $\begin{array}{l}\text { Competitividade do } \\
\text { produto no mercado }\end{array}$ & & & & & & & & & & & & V & V & V & $\mathrm{V}$ & $\mathrm{V}$ & V & & & $\mathrm{V}$ & 7 & $35 \%$ \\
\hline & $\begin{array}{c}\text { Produtividade da } \\
\text { empresa }\end{array}$ & & & & & V & & & $\mathrm{V}$ & & & $\mathrm{V}$ & $\mathrm{V}$ & $\mathrm{V}$ & & & $\mathrm{V}$ & $\mathrm{V}$ & & & $\mathrm{V}$ & 8 & $40 \%$ \\
\hline & Redução de custos & V & & V & & $\mathrm{V}$ & V & & V & V & V & $\mathrm{V}$ & V & $\mathrm{V}$ & & $\mathrm{V}$ & $\mathrm{V}$ & $\mathrm{V}$ & & & $\mathrm{V}$ & 14 & $70 \%$ \\
\hline & $\begin{array}{l}\text { Competência do } \\
\text { serviço prestado }\end{array}$ & & & & & $\mathrm{V}$ & V & & V & $\mathrm{V}$ & & $\mathrm{V}$ & $\mathrm{V}$ & $\mathrm{V}$ & & $\mathrm{V}$ & $\mathrm{V}$ & V & & V & $\mathrm{V}$ & 12 & $60 \%$ \\
\hline & Prestígio no mercado & & & & & V & & & & & & & V & & V & V & V & V & & & $\mathrm{V}$ & 7 & $35 \%$ \\
\hline \multirow{9}{*}{ 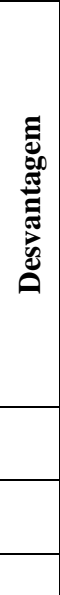 } & Qualidade do serviço & $\mathrm{D}$ & & & $\mathrm{D}$ & & & $\mathrm{D}$ & & & $\mathrm{D}$ & & & & & & & & $\mathrm{D}$ & $\mathrm{D}$ & & 6 & $30 \%$ \\
\hline & $\begin{array}{l}\text { Competitividade do } \\
\text { produto no mercado }\end{array}$ & $\mathrm{D}$ & $\mathrm{D}$ & & $\mathrm{D}$ & $\mathrm{D}$ & $\mathrm{D}$ & D & $\mathrm{D}$ & $\mathrm{D}$ & $\mathrm{D}$ & $\mathrm{D}$ & & & & & & & $\mathrm{D}$ & $\mathrm{D}$ & & 12 & $60 \%$ \\
\hline & $\begin{array}{c}\text { Produtividade da } \\
\text { empresa }\end{array}$ & $\mathrm{D}$ & $\mathrm{D}$ & & $\mathrm{D}$ & & D & D & & $\mathrm{D}$ & $\mathrm{D}$ & & & & $\mathrm{D}$ & $\mathrm{D}$ & & & $\mathrm{D}$ & $\mathrm{D}$ & & 11 & $55 \%$ \\
\hline & Redução de custos & & $\mathrm{D}$ & & & & & $\mathrm{D}$ & & & & & & & D & & & & $\mathrm{D}$ & $\mathrm{D}$ & & 5 & $25 \%$ \\
\hline & $\begin{array}{l}\text { Competência do } \\
\text { serviço prestado }\end{array}$ & $\mathrm{D}$ & $\mathrm{D}$ & & $\mathrm{D}$ & & & $\mathrm{D}$ & & & $\mathrm{D}$ & & & & $\mathrm{D}$ & & & & $\mathrm{D}$ & & & 7 & $35 \%$ \\
\hline & Prestígio no mercado & $\mathrm{D}$ & $\mathrm{D}$ & & $\mathrm{D}$ & & D & $\mathrm{D}$ & $\mathrm{D}$ & $\mathrm{D}$ & $\mathrm{D}$ & $\mathrm{D}$ & & $\mathrm{D}$ & & & & & $\mathrm{D}$ & $\mathrm{D}$ & & 12 & $60 \%$ \\
\hline & $\begin{array}{c}\text { Numero de vantagens } \\
\text { apontadas }\end{array}$ & 1 & 1 & 1 & 0 & 5 & 3 & 0 & 4 & 3 & 1 & 4 & 6 & 5 & 3 & 5 & 6 & 6 & 0 & 1 & 6 & 61 & \\
\hline & $\begin{array}{c}\text { Número de } \\
\text { desvantagens apontadas }\end{array}$ & 5 & 5 & 0 & 5 & 1 & 3 & 6 & 2 & 3 & 5 & 2 & 0 & 1 & 3 & 1 & 0 & 0 & 6 & 5 & 0 & 53 & \\
\hline & Maior número de: & $\mathrm{D}$ & $\mathrm{D}$ & $\mathrm{V}$ & $\mathrm{D}$ & $\mathrm{V}$ & $=$ & D & V & $=$ & $\mathrm{D}$ & $\mathrm{V}$ & $\mathrm{V}$ & $\mathrm{V}$ & $=$ & $\mathrm{V}$ & $\mathrm{V}$ & V & $\mathrm{D}$ & $\mathrm{D}$ & $\mathrm{V}$ & & \\
\hline
\end{tabular}

Na tabela 9 estão os resultados obtidos nas empresas sobre o que o contador dispõe de seus serviços ou o que a empresa solicita do profissional contábil para a realização de seus interesses. Os resultados apontaram que a maioria dos entrevistados, perante aos serviços contábeis levantados para a pesquisa, afirmaram que a análise da elaboração de balanços e demonstrações (89\%), encaminhar declarações (100\%), apuração e controle de lucros/prejuízos (89\%) e a elaboração de processos governamentais $(89 \%)$ foram pontos que destacaram diante dos outros como serviços feitos exclusivamente pelo contador. Percebeu-se também que algumas empresas não utilizam a reavaliação de ativos (56\%), mesmo existindo legislação (Lei 6404/76) prevendo as práticas para esse procedimento.

Tabela 9: Análise da prestação de serviços oferecido pelo contador, em \%: 
Análise dos fatores que levam as empresas de comércio varejista de materiais para construção a terceirizarem os serviços contábeis

José Edipoan Augusto de Souza Ribeiro

Laércio Juarez Melz

Priscila Meliane Leite dos Anjos

Marcelo Evandro Alves

\begin{tabular}{lccc}
\hline \multicolumn{3}{c}{ REFERENTE AOS SERVIÇOS CONTÁBEIS, O CONTADOR. } \\
\hline & FAZ & AJUDA A & A EMPRESA NÃ \\
UTILIZA \\
Análise de fluxo de caixa & $33 \%$ & $23 \%$ & $44 \%$ \\
Análise e elaboração de balanços e demonstrações contábeis & $89 \%$ & $11 \%$ & $0 \%$ \\
Formação de preço & $11 \%$ & $78 \%$ & $11 \%$ \\
Análise de tributos & $56 \%$ & $44 \%$ & $0 \%$ \\
Apuração e controle de lucros/prejuízos & $89 \%$ & $11 \%$ & $0 \%$ \\
Definição de metas & $12 \%$ & $44 \%$ & $44 \%$ \\
Planejamento estratégico & $12 \%$ & $44 \%$ & $44 \%$ \\
Orçamento empresarial & $12 \%$ & $44 \%$ & $44 \%$ \\
Análise/cálculo de custos & $22 \%$ & $67 \%$ & $11 \%$ \\
Encaminhar declarações - DACON/DIRF/DCTF/IRPF/DIPJ & $100 \%$ & $0 \%$ & $0 \%$ \\
Acompanhamento de metas & $12 \%$ & $44 \%$ & $44 \%$ \\
Reavaliação dos ativos & $44 \%$ & $0 \%$ & $56 \%$ \\
Depreciação dos ativos & $56 \%$ & $0 \%$ & $44 \%$ \\
Controle de estoque & $22 \%$ & $67 \%$ & $11 \%$ \\
Sped fiscal & $56 \%$ & $44 \%$ & $0 \%$ \\
Controle de rotatividade dos funcionários & $44 \%$ & $56 \%$ & $0 \%$ \\
Elaboração de processos junto aos órgãos governamentais & $89 \%$ & $11 \%$ & \\
\hline
\end{tabular}

\section{CONSIDERAÇÕES FINAIS}

$\mathrm{O}$ artigo teve o objetivo geral de verificar quais os fatores que levam as empresas varejistas de materiais de construção de Tangará da Serra - MT a terceirizarem a prestação de serviços. Foi analisado e apontado como objetivo específico que a prestação de serviços contábeis auxilia as empresas na tomada de decisão. Também foi verificado que a contratação dos serviços terceirizados contábeis possui vantagens e desvantagens, na qual é destacado um ponto importante, que caso seja mal utilizado pode se tornar um risco para a empresa, que é a redução de custos, pois não havendo uma administração correta e decidida pode ter a perda de qualidade do produto e a descentralização de informações. Obteve-se como fatores determinantes para a terceirização a qualidade nos serviços prestados e a redução de custos.

A Contabilidade dentro de uma organização passa a fazer parte fundamental nas tomadas de decisões. Algumas são as razões apontadas no artigo que mostram a importância e a necessidade de utilização do sistema de informações contábeis dentro do ambiente da administração empresarial, seja em forma de assessoria ou como uma ferramenta gerencial 
Análise dos fatores que levam as empresas de comércio varejista de materiais para construção a terceirizarem os serviços contábeis

José Edipoan Augusto de Souza Ribeiro

Laércio Juarez Melz

Priscila Meliane Leite dos Anjos

Marcelo Evandro Alves

para tomada de decisões. Assim, a prestação de serviços contábeis é uma ferramenta fundamental para que haja uma boa gestão da empresa, pois o empresário teria dados específicos sobre determinadas situações, seja elas: estoques, liquidez, custos das mercadorias, entre outros fatores. Esta prestação de serviço desde que, seja bem utilizada, pode trazer grandes contribuições para o sucesso empresarial, sua continuidade e para a tão desejada maximização da utilização dos recursos empresariais e do capital investido.

Contudo, novas pesquisas relacionadas ao assunto perante as outras empresas podem ser realizadas, sejam no ramo de vestuário, construtoras, automobilística, como também nas empresas de comércio de materiais de construções das demais regiões, não só de Mato Grosso, mas também do Brasil. A finalidade seria contribuir tanto aos contadores quanto aos administradores, para que haja harmonia em relação ao trabalho um para com o outro.

\section{REFERÊNCIAS}

ARRUDA, Carlos; COZZI, Afonso; SILVEIRA, Guilherme. Estratégias e Práticas de Corporate Venturing no Contexto Brasileiro. 2012.

BERNSTORFF, Vitor Hugo; CUNHA, João Carlos. O que as organizações buscam e alcançam com a terceirização em tecnologia da informação. Maio: 2005

BEUREN, Ilse Maria (org). Como elaborar trabalhos monográficos em contabilidade. São Paulo: Atlas, 2003.

COELHO, Alice Cristine Leal. A responsabilidade da administração pública pelos encargos trabalhistas decorrentes da contratação de serviços terceirizados. Tijucas: 2007.

CONSELHO REGIONAL DE CONTABILIDADE DO PARANÁ. Aspectos práticos: elaboração e apresentação conceitual de acordo com o IFRS. Junho: 2011.

ESPERANDIO, Alexandre dos Santos. MELO, Rodrigo Carlos de. MATA, Altair Roberto. Sistema público de escrituração digital sped fiscal - vantagens e importância. Julho: 2011.

FERREIRA, Aracéli Cristina de Sousa. DUTRA, René Gomes. CARDOSO, Ricardo Lopes. A economia da informação contábil. Novembro: 2000.

FIGUEIREDO, S.; FABRI, P.E. Gestão de empresas contábeis. São Paulo: Ed. Atlas, 2000. FORTES, José Carlos. Manual do Contabilista. Belém: Celigráfica, 2001.

IMHOFF, Márcia Moraes; MORTARI, Aline Perico. Terceirização, vantagens e desvantagens para as empresas. Santa Maria: 2005. 
Análise dos fatores que levam as empresas de comércio varejista de materiais para construção a terceirizarem os serviços contábeis

José Edipoan Augusto de Souza Ribeiro

Laércio Juarez Melz

Priscila Meliane Leite dos Anjos

Marcelo Evandro Alves

IUDÍCIBUS, Sérgio de (coord.). Contabilidade introdutória/ equipe de professores da Faculdade de Economia, Administração e Contabilidade da USP. 9. Ed. São Paulo: Atlas, 1998.

KOTLER, Philip. Administração de marketing: análise, planejamento, implementação e controle. 2. ed. São Paulo: Editora Atlas, 1992.

LAKATOS, Eva Maria; MARCONI, Marina de Andrade. Fundamentos de metodologia científica. $3^{\circ}$ edição. São Paulo: Atlas, 1991.

LEONE, George S. G. Curso de contabilidade de custos. São Paulo: Atlas, 1997.

LONDERO, Bruno Alex; PERES, Eliane; CHARAO, Renata. A contabilidade na administração das empresas. Santa Maria - RS: 2005.

LOPES, A. B.; MARTINS, Eliseu. Teoria da Contabilidade: uma nova abordagem. São

Paulo: Atlas, 2005.

MARION, José Carlos. Contabilidade Básica, 6 ed, São Paulo: Atlas, 1998.

MARTINS, Eliseu. Contabilidade de custos. São Paulo: Atlas, 1992.

MARTINS, Sérgio Pinto. A Terceirização e o direito do trabalho. São Paulo: Atlas, 2001.

MATTOS, Abreu Matos; DIAS, Juliana do Prado; GONÇALVES, Jocimara Grande. Estudo da viabilidade técnica e econômica da terceirização dos serviços contábeis nas indústrias de plásticos em Curitiba. Curitiba: 2006.

MULLER, Aderbal Nicolas; OLIVEIRA, Antonio Gonçalves. Contabilidade Empresarial. 2003.

NASI, Antônio Carlos. A contabilidade como instrumento de informação, decisão e controle da gestão. Revista do Conselho Regional de Contabilidade do Rio Grande do Sul, Porto Alegre, n.77, 1994.

NUNES, Jane D. S.; FREITAS, Luciana Q. de; A importância da informação contábil de acordo com os parâmetros éticos. Belo Horizonte: 2004.

NUNES, Sandra M. A. Terceirização de serviços contábeis: um estudo de caso na tropical calçados. Juína - MT: 2009. < http://www.biblioteca.ajes.edu.br>. Acesso em: 10 de Novembro de 2011.

OLIVEIRA, Alessandro Aristides de; SILVA, Andréia Regina da; ZUCCARI, Solange Maria de Paula; RIOS, Ricardo Pereira. A análise das demonstrações contábeis e sua importância para evidenciar a situação econômica e financeira das organizações. 2010.

OLIVEIRA, Luciano. Diferenças entre contabilidade gerencial e contabilidade financeira. Disponível em:

<http://www.editoraferreira.com.br/publique/media/toq36_luciano_oliveira.pdf $>$. Acesso em: 25 abr. 2012.

OTT, Ermani. Contabilidade Gerencial Estratégica: Inter-relacionamento da contabilidade financeira com a contabilidade gerencial. BASE - Revista de Administração e Contabilidade da Unisinos. São Leopoldo - RS: 2004.

PIVETTA, Geize. A utilização do fluxo de caixa nas empresas: um modelo para a pequena empresa. Santa Maria: 2005. 
Análise dos fatores que levam as empresas de comércio varejista de materiais para construção a terceirizarem os serviços contábeis

José Edipoan Augusto de Souza Ribeiro Laércio Juarez Melz

Priscila Meliane Leite dos Anjos

Marcelo Evandro Alves

QUEIROZ, Carlos Alberto Ramos Soares de. Manual de Terceirização. São Paulo. Editora STS, 1992.

RIBEIRO, Osni Moura. Estrutura e análise de balanços fácil, São Paulo: Saraiva 2009.

SÁ, Antonio Lopes. O mercado de trabalho de um profissional está atado à qualidade dos serviços. Rio de Janeiro, 2008. Disponível em:

<http://www.mscontabilidade.com.br/artigos.asp>. Acesso em: 07/04/2012.

SILVA, Maria Rosângela da. Identificação e análise da percepção de gestores de hotéis de Campos de Jordão em relação aos serviços de escritórios contábeis. São Paulo: 2009.

TASSO, Carla Cristina. A importância da contabilidade na estratégia das empresas.

Vitória/ES, maio/2005. Disponível em:

<http://www.Fiscosoft.com.br/main_index.php?home=home-Artigos \&m>. Acesso em: 08 de Setembro de 2011.

VOLNEI, Cézar Mauss; BLEIL, Claudecir; BONATTO, Aline; OLIVEIRA, Camila Silva de; SANTOS, Getúlio Zanatta dos. A evolução da contabilidade e seus objetivos. Canoas - RS: 2007. 